A N N A L E S Annales de Bretagne et des Pays de l'Ouest

\title{
Plouviez David, La Marine française et ses réseaux économiques au XVIII e siècle
}

\section{Gérard Le Bouëdec}

\section{(2) OpenEdition \\ 1 Journals}

\section{Édition électronique}

URL : http://journals.openedition.org/abpo/2999

DOI : 10.4000/abpo.2999

ISBN : 978-2-7535-4130-6

ISSN : 2108-6443

\section{Éditeur}

Presses universitaires de Rennes

Édition imprimée

Date de publication : 15 avril 2015

Pagination : 204-206

ISBN : 978-2-7535-4128-3

ISSN : 0399-0826

\section{Référence électronique}

Gérard Le Bouëdec, "Plouviez David, La Marine française et ses réseaux économiques au XVIIIe siècle », Annales de Bretagne et des Pays de l'Ouest [En ligne], 122-1 | 2015, mis en ligne le 21 avril 2015, consulté le 23 septembre 2020. URL : http://journals.openedition.org/abpo/2999 ; DOI : https://doi.org/ $10.4000 /$ abpo. 2999 
Plouviez, David, La Marine française et ses réseaux économiques au xVIII siècle, Paris, Les Indes Savantes, 2014, 541 p., préface de Martine AcERRA

David Plouviez a soutenu en 2009 à l’Université de Nantes sous la direction de Martine Acerra sa thèse intitulée, « De la terre à la mer. La construction navale militaire française et ses réseaux économiques aux xvIII ${ }^{e}$ siècle ». Depuis, nous avions dû nous contenter de ses contributions dans des colloques ou dans des articles ; voici donc enfin la version publiée attendue, un très bel ouvrage de 541 pages. Lors d'une session du GIS d'Histoire maritime à Bordeaux en 2008, Michel Vergé-Franceschi soulignait que l'histoire maritime militaire à l'époque moderne connaissait un certain épuisement après une période flamboyante. Un doctorant présent, David Plouviez, était alors intervenu pour souligner que l'étude des approvisionnements des arsenaux de la Marine pouvait constituer un des axes de renouvellement des travaux sur la marine militaire et les arsenaux à l'époque moderne. Initié par ses travaux sur les approvisionnements de la compagnie des Indes de 1737 à 1770, l'auteur du compte-rendu avait quelques raisons de se plonger dans ce livre passionnant.

Le navire de guerre est d'abord une affaire de terriens. La construction navale c'est d'abord une affaire de bois, de chanvre et de métaux et les arsenaux sont de véritables entonnoirs ou s'engouffrent des masses de matières premières. Les étudier, c'est écrire une histoire des circuits de ces produits à l'échelle nationale et internationale, des réseaux de transports qui maillent le territoire de la première industrie de France et à l'échelle de la chaîne logistique du premier employeur. Ainsi David Plouviez réalise un croisement entre l'histoire de la marine militaire, ses arsenaux, et son territoire de projection et une histoire économique et sociale des espaces productifs.

L’administration de la Marine a dû d'abord construire un corpus juridique pour élaborer des documents qui sont de véritables cahiers des charges précisant ses tarifs, la qualité des matériaux, les calendriers de livraisons, les modalités de livraisons avant de lancer ses appels d'offre afin de se prémunir contre les entrepreneurs indélicats et les aléas conjoncturels. Ce travail auquel ont participé tous les membres gestionnaires et techniciens de la marine est opérationnel au moins dans le dernier tiers de $\mathrm{XVIII}^{\mathrm{e}}$ siècle. C'était une nécessité quand Maurepas décide d'intégrer la Marine dans l'économie de marché et de confier la quasi totalité des besoins des arsenaux à des fournisseurs privés. David Plouviez dresse une typologie du réseau de fournisseurs nationaux et internationaux en trois grandes catégories : les vendeurs occasionnels qui évoluent à proximité des arsenaux, les marchands régionaux pas toujours faciles à identifier, et les grands fournisseurs de la Marine issus du grand négoce, de la noblesse d'affaires et de la finance.

L'auteur consacre une partie au bois, dont la disponibilité est un enjeu stratégique, particulièrement après la guerre de Sept Ans. La France n’a pas manqué de bois de construction mais la collecte de plus en plus forte et éloignée, jusqu'à $500 \mathrm{~km}$ de Brest et Rochefort, aboutit à la fin du xvIII siècle à puiser dans des qualités tout juste acceptables. La flotte du Levant est italienne, écrit David Plouviez, pour souligner que Toulon eut recours à des approvisionnements italiens quand les ports du Ponant pouvaient compter sur des importations des bois des pays du Nord. Le recours aux mâts français, bien que décriés dans les ports de l'Atlantique, était nécessaire, surtout à Toulon. La dépendance pour la mâture de la taïga des rives de la Baltique est évidente, mais c'est surtout à partir de la guerre d'Indépendance américaine, du fait de l'assouplissement de la position de la Russie et de la moindre pression de l'Angleterre qui s'approvisionne en Amérique du Nord, que les livraisons de mâts livoniens arrivent plus facilement. Mais, tout comme pour le bois de construction, la France n'a pas su tirer partie des ressources de Nouvelle France et des ÉtatsUnis.

La flotte de guerre est aussi à la base d'un double développement industriel dans le secteur de l'industrie du vent et dans le domaine métallurgique. La Marine a recours aussi bien aux ateliers de production toilière des arsenaux qu'aux manufactures éclatées dans des espaces de productions ou concentrées. Elle a d'ailleurs soutenu la création de manufactures privilégiées. Contrairement à ce que l'on observe dans le domaine métallurgique, elle n'a pas su concentrer la production autour de quelques pôles, un par façade littorale, et faire le choix entre des manufactures intra-arsenal et des établissements externalisés. La France reste dépendante des importations étrangères de matières premières brutes ou semi-finies de fer et de cuivre notamment de Suède, de Russie, de Norvège et d'Espagne, et elle a de fait appliqué une politique douanière favorable aux achats extérieurs. La création de fonderies et de forges qui doivent disposer d'infrastructures hydrauliques et thermiques nécessite des 
capitaux importants dont ne disposent qu'une trentaine d'entrepreneurs issus notamment de la noblesse. Mais le passage d'un réseau éclaté à une concentration en quelques très grosses entreprises comme Clavières, La Ruelle, Le Creusot, Indret, notamment après la guerre de Sept Ans avec le contrat signé avec Babaud de La Chaussade, et surtout à partir des années 1780, réduit le nombre d'interlocuteurs de la Marine à quatre ou cinq. C'est alors l'affirmation de groupes financiers et d'entrepreneurs ouverts aux nouvelles techniques de production, notamment dans l'artillerie et la fabrication des ancres, qui préfigurent les ingénieurs techniciens des usines. La production d'acier se concentre autour du complexe Nivernais de la Chaussade, finalement acquis par l'État sous l'impulsion de Necker et de Castries, de la fonderie de Ruffec en contrat longue durée avec la Marine tandis que l'industrie du canon s'organise sur les trois sites du Creusot, Ruelle, et Indret avec un investissement de l'État particulièrement soutenu jusqu'en 1782. Au final, c'est la réussite d'un complexe métallurgique de technologie de pointe à l'anglaise et d'économie mixte. Mais face à l'importance des besoins financiers, les investisseurs issus de la noblesse d'affaires n'ont pu s'appuyer comme leurs homologues anglais sur un véritable réseau bancaire, ce qui les fragilise.

C'est aussi un défi que de connecter les espaces d'approvisionnement avec les ports arsenaux. La question des transports dont le coût représente parfois $50 \%$ du prix de la marchandise est cruciale. La Marine a dû mobiliser tous les moyens de transports fluviaux, terrestres et maritimes et favoriser la multimodalité. Du fait de l'absence d'une flotte spécialisée et de moyens propres, la Marine a recours au marché concurrentiel du transport. L'ampleur des flux destinés à la Marine a dû peser sur la croissance des tonnages des caboteurs, l'adaptation des arrimages sur le pont et dans la coque, la manutention et les infrastructures portuaires. Mais il faut aussi considérer que le marché du transport maritime est réactif et a su aussi répondre à la demande d'un des plus gros clients chargeurs de produits pondéreux.

Disposer d'une couverture de l'ensemble du territoire pour connaître et exploiter ses ressources était un enjeu pour la Marine. Du fait de l'extension continue des aires d'approvisionnement, elle intervient au-delà des espaces qui relèvent des Ponts et Chaussées pour construire des chemins et creuser les rivières afin d'accéder aux ressources des espaces de production, comme elle le fit avec l'aménagement du Doubs. Elle innove également en faisant du Creusot et d'Indret de véritables laboratoires industriels qui préfigurent la méthode que la Marine développera au XIx ${ }^{\mathrm{e}}$ siècle dans ses ateliers du fer et de la vapeur : expérimenter pour acquérir du savoir et du savoir faire avant de procéder éventuellement à leur généralisation.

Jean Meyer avait coutume de dire que Versailles et la Marine de guerre avaient été les moteurs du développement économique sous Louis XIV. Par les thèses qu’il a dirigées, il a contribué à un renouvellement de l'histoire de la Marine par l'étude globale des arsenaux. David Plouviez démontre le rôle majeur de la Marine et donc de l'État dans le développement de l'appareil industriel et du réseau de transport de la France du xvIII siècle. La Marine conservera un rôle majeur sinon pionnier dans le développement des technologies du fer et de la vapeur jusqu'aux années 1850. Ces travaux ouvrent donc des perspectives comparatives sur la place de l'approvisionnement des marines européennes dans l'économie atlantique - voir à ce sujet les travaux sur « défense et colonie dans le monde atlantique » dirigé par David Plouviez et publié aux PUR en 2014 - et des jalons pour une problématique sur le temps long sur Marine militaire et développement économique. 